\title{
PERFORMANCE AND COMPETITIVE ORIENTATION: TEAM DYNAMICS IN TEST MATCH CRICKET
}

\author{
Andy Adcroft and Jon Teckman
}

$\underline{\text { Introduction }}$

The primary aim of this paper is to consider the relationship between team composition and team results in international test match cricket. The paper argues that there is a relationship between team composition and team outcome but that the causal nature of that relationship is not always clear. In making these arguments, the paper is organised in a straightforward manner. The first section considers the literature on team dynamics and highlights the uncertainty in the literature about the direct relationship between diversity and results. The section considers the main ways in which diversity has been examined in previous studies and suggests that examining diversity on the basis of performance and competitive orientation is useful as it cuts across demographic, psychological and temporal boundaries which form the basis for most studies to date. The second section explains the methodology employed in the study through a discussion of the measurement of performance and competitive orientation in international test match cricket and the selection of a sample from which reliable and valid conclusions can be drawn. The following section presents the findings from the research and focuses on explanations as to why the best and worst teams have the results they do and why other teams find themselves within certain clusters. The final section offers a discussion of these findings in relation to the theoretical grounding of the paper and, in doing this, provides conclusions and suggestions for future research.

\section{$\underline{\text { Literature Review }}$}

In defining a team, much of the literature offers the view that a team is characterised by being a collection of two or more individuals. It is, however, important to go deeper in order to differentiate a team from, say, a group. In making this distinction, Cohen and Bailey (1997) and Guzzo and Dickson (1996) suggest that it rests on the identification and recognition of the team as being a social entity not only by members of that team but also by outsiders. Cohen and Bailey go further and suggest that identification may be developed through a team having a clear purpose that is shared and accepted by all members and understood by outsiders. Again, what may differentiate a team from other collections of individuals is the issue of interdependency. Mattieu et al (2000) suggest that central to any team are "people who interact dynamically, interdependently and adaptively" (p. 273) where both the actions of individuals and the behaviour and outcomes of the collective, are determined by the relationships within, and constituents of, the team.

This view of teams as "complex, adaptive and dynamic systems" (McGrath et al, 2000, p. 95) means that the study of team composition is a necessarily complex one. Le Pine et al (1997) suggest that this complexity is the product of the vertical and horizontal characteristics of the team where vertical characteristics refer to issues of power distribution within the team and horizontal characteristics refers to the distribution of expertise. This suggestion that a team will be a hierarchy with different elements of knowledge, skills and abilities distributed across it is reasonably common across much of the literature and, for example, gives rise to Salas et al's (2000) different dimensions across which the nature and working of a team can be analysed. These different dimensions include the capacity of the team to adapt to both internal and external changes, the monitoring of both team and individual performance, how teams are led and managed and the roles of communication and decision making in team processes.

One of the most popular analytical models used in the investigation of team dynamics is the input-process-output (IPO) model (see, for example, Barrick et al, 1998) which suggests that 
what is achieved by any team is the result of the relationship between the elements which go into creating that team and what happens inside the team. The key issues for the inputs of the team include the attributes of its members, the number of members and how they are structured and organised along with the goals of the team and rewards that may accrue from meeting those goals. Like Salas et al, Barrick et al suggest that some of the key process issues are communication, leadership and conflict management. McGrath et al develop this point further and suggest that the results obtained by any team are the results of a number of dynamics. For example, at the broadest possible level, the contextual dynamics of a team determines the size and depth of the talent pool on which the team can draw its members which, in turn, shapes the global dynamics of the team and how variables such as status, leadership and performance influence outcomes. Finally, the local dynamics of the team considers the activities carried out by different elements within it.

In analysing half a decade of team research, Bettenhausen (1991) suggested that there will always be more questions than answers about what makes for an effective team and that any judgement will always be influenced by the type, location and purpose of the team under examination. This uncertainty is reflected by Barrick et al who argue that whilst "the composition of the team has long been hypothesised to influence team processes and outputs" (p. 377) it is still the case that "little is known about the relationship between team composition variables and team effectiveness" ( $\mathrm{p}$. 387). This theoretical and empirical deficiency is, however, not universally accepted. Guzzo and Dickson, for example, argue that the effectiveness of any team is determined by a combination of design, process and operating conditions and conclude that "team effectiveness is well served by diverse members" (p. 331). This view is shared by Katzenbach (1997) who also identifies key issues in team effectiveness such as purpose, the skills mix, commitment and accountability.

In discussing effectiveness, Cohen and Bailey argue that team composition is one of the most important factors. Internally, composition matters because it plays a fundamental role in a series of design activities which may determine the overall role that the team is to play: The interactions between members, what Cohen and Bailey call "process factors", and the shared understandings of members, "psychosocial factors" are crucial in the ability of the team to meet any challenges from external turbulence (pp. 243-244). Stevens and Campion (1994) suggested that a useful way of thinking about this composition dimension is in terms of knowledge, skills and abilities (KSAs). Diversity is an important issue and the recognition that each individual member of the team will have a different blend of KSAs, some of which can be characterised as "interpersonal" such as collaboration and communication and some as "self-management" such as goal setting and task co-ordination (p. 505). Woodman et al (1993) examine these composition issues in the specific context of creativity and note that, as an outcome, team creativity "is not the simple aggregate" of its members but it is "clearly a function of the creativity of individuals" (p. 304).

In examining how teams are created, Barry and Stewart (1997) offer a perspective based around how individuals make contributions to teams in which they are members. Elaborating on the IPO model, they suggest that the inputs required by any team will fall into two categories: First, task inputs which involve the productive needs of the team such as ensuring that individuals fulfil their own roles and responsibilities and, second, socio-emotional inputs which focus more on the people aspect of the team and involve the facilitation of interactions. Jackson (1992) goes further and identifies three broad areas where how a team is assembled will have a significant effect; the ability of the team to be creative, the ability of the team to solve problems and the ability of the team to execute the task for which it was formed. Reagans et al (2004) develop this issue of blend further and draw attention to two significant barriers to getting the right blend of people. First are political barriers whereby circumstances may dictate the inclusion or exclusion of certain individuals and, second, there are resource barriers whereby the pool of KSAs available to any organisation will always be limited. 
Team composition is a central feature of much of the literature on team processes especially in the areas of team diversity and its impact on what teams achieve and how they achieve it. For example, Wiersema and Banter (1992) discussed the issue of diversity in relation to how it may affect teams in four areas: The receptivity of the team to change, the willingness of the team to take risks, the openness of the team to different perspectives and the ability of the team to act in an innovative or creative manner. Wiersama and Banter's conclusions were that each of these were affected by the diversity of the team without there being any hard and fast rules about what those effects would be. This lack of clear conclusions is echoed by Harrison et al (2002) who suggest that "paths linking work team diversity to team functioning and performance outcomes are complex" (p. 1029). The main cause of this complex relationship is the evidence that diversity has both positive and negative effects on team processes and outcomes. On the one hand, evidence suggests that low levels of diversity can have a positive effect on team cohesion (see, for example, Perretti and Negro, 2007) but can have a negative effect on creativity, innovation and excitement (see, for example, Stahl et al, 2007).

Harrison et al identified two main types of diversity which have been the focus for much research in this area. Diversity has been examined in demographic terms through, for example, the age, gender or race of team members. It has also been examined from the perspective of psychological diversity and issues such as the personality, values, attitudes and beliefs of team members. In examining demographic diversity, Hambrick et al (1996) suggest that young and highly educated teams may be more innovative whereas psychologically diverse teams tended to have a higher propensity for action. Hambrick et al concluded that, across these two types, "diversity enhances the breadth of perspective, cognitive resources and overall problem solving capacity" (p. 662). The third type of diversity, which has appeared more prominently in the literature in recent years, is that of temporal diversity which focuses on the dual issues of how long a team has been together and how frequently new members are introduced into established teams (see, for example, Katzenbach). In both cases, low levels of diversity in stable teams has the benefit of improving team processes but the drawbacks of reducing creativity and the skill pool on which the team draws. In cutting across these types of diversity, we now turn to discuss the performance and competitive orientations of team members.

Adcroft and Teckman (2008) define performance orientation in terms of the internal characteristics of any sporting team; "its collection of activities and systems and the way in which they are managed" (p. 603). Thus a team with a high performance orientation will have a strong internal focus (Simons et al, 2000) which will tend to concentrate on the contributions of each team member. For example, Huddleston and Garvin (1995) argue that what matters is the effectiveness of individual contributions and processes much more than any collective or shared team outcome. Thus for both the managers and members of such teams, Stiles et al (1997) identify the importance of rehearsal and practice of set routines and patterns of behaviour and the need for those teams to operate in relatively stable environments if they are to succeed. By way of contrast, Adcroft and Teckman suggest that a competitive orientation is much more externally driven and focuses on the relationships between competitors in any given contest. This competitive orientation, rather than being concerned with team processes, is concerned with outcomes and what Ryckman et al (1997) describe as a need to "compete and win (and avoid losing) at any cost" (p. 271). A competitive orientation is summed up by Gatignon and Xuereb (1997) through the development of a competitive advantage by innovating and taking risks.

In discussing performance and competitive orientations, three points are crucial for the purposes of this paper. First, teams will exhibit a blend of performance and competitive behaviours. Adcroft and Teckman discuss this issue in terms of positions that any given team may occupy ranging from the ideal position where there are high performance and competitive behaviours to a worst position where low levels of each orientation are exhibited. Second, a team's blend of performance and competitiveness is determined by its membership 
which follows on from Woodman et al's conclusion about team characteristics being a function, rather than an aggregate, of its individual members' characteristics. Finally, the diversity of performance and competitiveness in a team cuts across the traditional lines of enquiry into diversity; it is a function of demographic, psychological and temporal diversity. The next section of the paper explains how these theoretical issues are to be examined in the context of international test match cricket.

\section{Methodology}

Test match cricket is an ideal sport to examine the blend of performance and competitiveness within competing teams for both theoretical and practical reasons. Test match cricket is a useful illustration of Reagens et al's point about the availability of finite resources; given the strict eligibility criteria that must be met before a player can play test match cricket, all teams will have access to limited playing resources and, by implication, a limited pool of KSAs on which they can draw. In examining how these finite resources are blended to deliver individual performances and collective competitive outcomes, we draw on the characteristics of performance and competitive orientation in a sporting context developed by Adcroft and Teckman which are shown in Table 1.

Table 1: $\quad$ Key characteristics of performance and competitive orientation in a sporting context

\begin{tabular}{|c|c|}
\hline PERFORMANCE ORIENTATION & COMPETITIVE ORIENTATION \\
\hline $\begin{array}{l}\text { Mindset } \\
\text { - Internal and self centred } \\
\text { - Process driven, how things are done is } \\
\text { important } \\
\text { The aesthetics of performance really } \\
\text { matter }\end{array}$ & $\begin{array}{l}\text { Mindset } \\
\text { - External and relative } \\
\text { - Outcomes and what is achieved } \\
\text { - Aesthetics are an optional extra and can } \\
\text { be easily discarded }\end{array}$ \\
\hline $\begin{array}{l}\text { Objectives } \\
\text { - Process based } \\
\text { - Arrived at through a deconstructive } \\
\text { process } \\
\text { - Aimed at self, rarely externally } \\
\text { compared } \\
\text { - Sliding scale of achievement } \\
\end{array}$ & $\begin{array}{l}\text { Objectives } \\
\text { - } \text { Outcome/Result driven } \\
\text { - } \text { Determined in the contested arena } \\
\text { - Clear emphasis on current, not future, } \\
\text { contests }\end{array}$ \\
\hline $\begin{array}{l}\text { Focus } \\
- \text { Reliability within a set of parameters } \\
\text { - Focus on improvements over time and } \\
\text { fulfilling potential } \\
\text { - Physical and tangible measures of } \\
\text { performance }\end{array}$ & $\begin{aligned} \text { Focus } & \\
\text { - } & \text { Reliability under pressure } \\
\text { - } & \text { Winning when it counts } \\
\text { - } & \text { Mentcome/Results driven } \\
& \end{aligned}$ \\
\hline $\begin{aligned} & \text { Style } \\
& \text { - } \text { Rigid, inflexible, prescriptive } \\
& \text { - } \text { Pre-set patterns are important } \\
& \text { - } \text { Rehearsal and practice } \\
&\end{aligned}$ & $\begin{aligned} & \text { Style } \\
&- \text { Adaptive to circumstances } \\
&- \text { Improvisation/Innovation/ Emergent } \\
& \text { - } \text { Empowering experienced team members } \\
&\end{aligned}$ \\
\hline
\end{tabular}

Source: Adcroft and Teckman, 2008, p. 605

In practical terms, cricket is a multi-dimensional and complex sport and so, at any given time, teams will be engaged in different activities: one team will be trying to score runs and the other will be trying to take wickets. This gives rise to a whole series of possibilities in terms of measurements and variables; the statistics in this paper are all taken from the website www.cricinfo.com which is the definitive source for cricket statistics. Performance and competitive orientation can be measured in a number of different ways which can be applied without bias across all teams. Cricket is a sport where the test match version is played by a relatively small number of countries and so it is simple to generate a genuinely representative 
sample. We begin, therefore, with an explanation of how we have determined a sample of matches to be analysed.

The sample we have chosen is built around eight of the ten teams currently playing test match cricket. The two teams that have been excluded are Zimbabwe and Bangladesh. These teams have been excluded because of their lack of experience in this form of the game. Zimbabwe, for example, have played just 88 test matches in their history (of which they have won less than $10 \%$ ) and Bangladesh currently have just one win from the 50 or so test matches that they have competed in. For the remaining eight teams, we have examined the 100 test matches played up to the series which straddled the end of 2006 and the start of 2007. To be included a test match had to have had a definite win/lose outcome or a minimum of 300 overs had to have been bowled. This means that matches with, for example, contrived results or matches significantly shortened by the weather have been excluded as have forfeited and abandoned matches. All teams have played each other on a number of occasions which allows for the identification of patterns and trends.

We now turn to discuss the composition of the player sample for each team. There are two specific problems that the selection of players has to overcome. First, there will always be a number of players who play too few matches for any meaningful analysis to be carried out. For example, 15 players who represented Australia in the sample did so on 5 or fewer occasions. The second problem is any sample of consecutive matches will automatically include either players who are at the end of their careers or players who are at the start of their careers. For example, Mike Atherton played over 100 test matches for England but only the final quarter of these were played in the time period under discussion whilst Shahid Afridi has played roughly the same number of games in the sample for Pakistan but these were his first appearances in test matches. We have mitigated the effects of this by only considering players who have played in at least $20 \%$ of the test matches under examination for each country. The details of our player sample is contained in Table 2 below.

Table 2: $\quad$ Sample of players for each team in the 100 test matches

\begin{tabular}{|l|c|c|c|c|c|c|}
\hline Team & $\begin{array}{c}\text { Total } \\
\text { Players } \\
\text { Used }\end{array}$ & $\begin{array}{c}\text { Total } \\
\text { Batsmen } \\
\text { Used }\end{array}$ & $\begin{array}{c}\text { Total } \\
\text { Bowlers } \\
\text { Used }\end{array}$ & $\begin{array}{c}\text { Players } \\
\text { playing 20 or } \\
\text { more games }\end{array}$ & $\begin{array}{c}\text { Batsmen } \\
\text { playing 20 } \\
\text { or more } \\
\text { games }\end{array}$ & $\begin{array}{c}\text { Bowlers } \\
\text { playing 20 } \\
\text { or more } \\
\text { games }\end{array}$ \\
\hline Australia & 40 & 20 & 21 & 16 & 10 & 6 \\
\hline England & 68 & 29 & 41 & 20 & 14 & 7 \\
\hline India & 67 & 37 & 31 & 14 & 7 & 7 \\
\hline New Zealand & 71 & 35 & 38 & 17 & 12 & 7 \\
\hline Pakistan & 72 & 43 & 31 & 18 & 10 & 9 \\
\hline South Africa & 51 & 26 & 28 & 21 & 15 & 9 \\
\hline Sri Lanka & 60 & 31 & 30 & 12 & 7 & 5 \\
\hline West Indies & 70 & 39 & 34 & 17 & 10 & 7 \\
\hline
\end{tabular}

Source: www.cricinfo.com

In measuring the performance and competitive orientations of these players, the central issue to be addressed is that of comparability; how does, for example, scoring 200 runs against a weak bowling attack like New Zealand compare with scoring 100 runs against a strong bowling attack like Australia? Our argument is that having clear measures of performance and competitiveness should help deal with this problem. In measuring performance across the two different activities of batting and bowling we have generated measures in four broad categories; Aggregate measures, Match by Match measures, Landmark measures and Team Contributions. Aggregate measures are the runs scored or wickets taken across the whole time period by individual players and so reward longevity and those players whose performance has consistently maintained their position in the team. Match by Match measures reflect the 
performance of players at a more micro-level and how they perform in an individual innings. Landmark measures assess the performance of players in reaching individual landmarks such as centuries or 5 wicket hauls and Team Contributions assesses how an individual's performance fits in with the team by assessing, for example, the strike rate of a batsman or the economy rate of a bowler. Table 3 summarises the performance measures used.

Table 3: $\quad$ Performance Measures for Batting and Bowling

\begin{tabular}{|c|c|c|}
\hline Type of Measure & Batting & Bowling \\
\hline Aggregate measures & $\begin{array}{l}\text { - Total runs scored in } \\
\text { matches played in sample }\end{array}$ & $\begin{array}{l}\text { - Total wickets taken in matches } \\
\text { played in sample }\end{array}$ \\
\hline $\begin{array}{l}\text { Match by Match } \\
\text { measures }\end{array}$ & $\begin{array}{l}\text { Average runs scored per } \\
\text { completed innings } \\
\text { Average runs scored per } \\
\text { match }\end{array}$ & $\begin{array}{l}\text { - } \begin{array}{l}\text { Average number of wickets } \\
\text { taken per innings }\end{array} \\
\text { - } \quad \text { Runs conceded per wicket taken } \\
\text { - } \quad \text { Overs bowled per wicket taken }\end{array}$ \\
\hline Landmark measures & $\begin{array}{l}\text { - Frequency of centuries } \\
\text { scored }\end{array}$ & $\begin{array}{ll}\text { - } & \text { Frequency of } 5 \text { wickets taken } \\
\text { per innings } \\
\text { - } \\
\text { Frequency of } 10 \text { wickets taken } \\
\text { per match }\end{array}$ \\
\hline Team Contribution & $\begin{array}{l}\text { - } \begin{array}{l}\text { Runs scored per } 100 \text { balls } \\
\text { faced }\end{array} \\
\end{array}$ & $\begin{array}{ll} & \text { Runs conceded per wickets } \\
\text { taken }\end{array}$ \\
\hline
\end{tabular}

A key issue is how these measures can be amalgamated in a way that is coherent and allows for a review of the overall position in terms of performance orientation. In following previous research in this area we have decided to use index numbers as the basis for creating an overall performance measurement score. The result of each of these measures has been indexed with the leading player based at 100 . The totals for each measure are added together to give an overall score for performance. For the ease of interpretation, this score is then indexed with the highest scoring individual based at 100. An example for this for 8 of the 85 batsmen in the sample and 8 out of the 57 bowlers in the sample is shown in Table 4 below. 
Table 4: $\quad$ Performance Measurement of 8 Batsmen and 8 Bowlers

\begin{tabular}{|c|c|c|c|c|c|c|c|c|}
\hline \multicolumn{9}{|l|}{ (1) Batting } \\
\hline & Ponting & Thorpe & Dravid & Horne & $\begin{array}{l}\text { Afrid } \\
\mathrm{i}\end{array}$ & Cullinan & Dilshan & Lara \\
\hline Total runs scored & 96 & 39 & 100 & 17 & 21 & 34 & 19 & 97 \\
\hline $\begin{array}{l}\text { Average runs per } \\
\text { innings }\end{array}$ & 100 & 78 & 86 & 41 & 59 & 86 & 50 & 83 \\
\hline $\begin{array}{l}\text { Average runs per } \\
\text { match }\end{array}$ & 100 & 78 & 92 & 54 & 71 & 85 & 56 & 100 \\
\hline $\begin{array}{l}\text { Centuries scored per } \\
\text { innings }\end{array}$ & 100 & 62 & 57 & 19 & 52 & 90 & 19 & 71 \\
\hline Runs per 100 balls & 71 & 69 & 48 & 45 & 100 & 57 & 63 & 67 \\
\hline Total & 467 & 325 & 382 & 176 & 304 & 352 & 208 & 418 \\
\hline Performance Index & 100 & 70 & 82 & 38 & 65 & 75 & 44 & 90 \\
\hline \multicolumn{9}{|l|}{ (2) Bowling } \\
\hline & Lee & Giles & Khan & Nash & Younis & $\mathrm{Nel}$ & Murali & Walsh \\
\hline $\begin{array}{l}\text { Wickets taken per } \\
\text { innings }\end{array}$ & 57 & 46 & 43 & 51 & 49 & 54 & 100 & 70 \\
\hline $\begin{array}{l}\text { Runs conceded per } \\
\text { wicket taken }\end{array}$ & 67 & 52 & 55 & 71 & 66 & 64 & 92 & 93 \\
\hline $\begin{array}{l}\text { Overs bowled per } \\
\text { wicket taken }\end{array}$ & 85 & 53 & 62 & 67 & 77 & 71 & 79 & 78 \\
\hline $\begin{array}{l}5 \text { wickets taken per } \\
\text { innings }\end{array}$ & 23 & 19 & 16 & 23 & 3 & 23 & 100 & 42 \\
\hline $\begin{array}{l}10 \text { wickets taken per } \\
\text { match }\end{array}$ & 0 & 0 & 0 & 19 & 10 & 19 & 100 & 14 \\
\hline Economy Rate & 56 & 69 & 62 & 75 & 60 & 64 & 82 & 85 \\
\hline Total wickets taken & 45 & 29 & 22 & 17 & 27 & 19 & 100 & 37 \\
\hline Total & 332 & 268 & 261 & 323 & 292 & 314 & 652 & 420 \\
\hline Performance Index & 51 & 41 & 40 & 49 & 45 & 48 & 100 & 64 \\
\hline
\end{tabular}

Source: $\underline{w w w . c r i c i n f o . c o m}$

In shifting from performance to competitiveness, our assumption is that players with a high competitive orientation are more likely to perform well when the challenge faced is at its highest. It is, therefore, reasonable to briefly discuss what we would expect to see from a competitive player in test match cricket. The theoretical basis of the paper would suggest such a player would have an ability to contribute to the team even when not performing at an optimal level and an ability to perform under the most testing conditions such as in matches played away from home or against the best opposition. We have generated five measures of competitiveness in batting and 7 measures in bowling which we have grouped into three categories: Team Contribution, Unfriendly Circumstances and Quality of Opposition. As with performance orientation, Team Contribution measures the ability of individual players to contribute positively to the team dynamics under testing conditions and so measures the extent to which a batsmen can bat for long periods or a bowler take wickets when faced with high levels of internal competition. The measures for Unfavourable Conditions focus on performance overseas. All the measures used are presented in Table 5. 
Table 5: $\quad$ Competitiveness Measures for Batting and Bowling

\begin{tabular}{|c|c|c|}
\hline Type of Measure & Batting & Bowling \\
\hline Team Contribution & - Balls faced per innings & $\begin{array}{ll} & \text { Top } 6 \text { opposition } \\
\text { wickets taken } \\
\text { - } \\
\text { Degree of internal } \\
\text { competition for wickets }\end{array}$ \\
\hline Unfriendly Conditions & $\begin{array}{ll}\text { - } & \text { Average runs per } \\
\text { innings scored overseas }\end{array}$ & $\begin{array}{l}\text { Average wickets per } \\
\text { innings taken overseas }\end{array}$ \\
\hline Quality of Opposition & $\begin{array}{ll}- & \text { Weighted runs scored } \\
\text { - } & \text { Average weighted runs } \\
\text { scored per innings } \\
\text { - } & \text { Frequency of weighted } \\
\text { centuries scored }\end{array}$ & $\begin{array}{ll}\text { - } & \text { Weighted wickets } \\
\text { taken per innings } \\
\text { - } \\
\text { Runs conceded per } \\
\text { weighted wicket taken } \\
\text { - Overs bowled per } \\
\text { weighted wicket taken } \\
\text { Weighted wickets } \\
\text { taken }\end{array}$ \\
\hline
\end{tabular}

The quality of opposition is assessed on the basis of batting and bowling performance discussed earlier; the intention is to see how individual batsmen fare against bowling of varying quality and how individual bowlers fare against batting of variable quality. We assume that competitive players will score runs or take wickets against the best opposition. In calculating the quality of opposition, an average is taken of the performance scores of all batsmen and all bowlers for each team which is then used to provide a weighting for each players performance. This process is illustrated in Table 6 using Australia and the West Indies as examples. Under this weighted calculation, runs scored against the best bowling carry a higher value than runs scored against weak bowling and, similarly, wickets taken against the best batting carry the most weight. 
Table 6: $\quad$ Quality of Opposition Weightings for Australia and the West Indies

\begin{tabular}{|c|c|c|c|}
\hline \multicolumn{4}{|l|}{ (1) Bowling } \\
\hline \multicolumn{2}{|c|}{ Australia } & \multicolumn{2}{|c|}{ West Indies } \\
\hline Player & Performance Score & Player & Performance Score \\
\hline Kasprowich & 42 & Ambrose & 58 \\
\hline McGill & 52 & Walsh & 64 \\
\hline McGrath & 71 & Hooper & 34 \\
\hline Gillespie & 50 & Dillon & 43 \\
\hline Warne & 72 & Collins & 36 \\
\hline \multirow[t]{2}{*}{ Lee } & 51 & Collymore & 48 \\
\hline & & Edwards & 36 \\
\hline Average & 56.1 & Average & 45.6 \\
\hline Index & 100 & Index & 82 \\
\hline Weighting & 1.0 & Weighting & 0.82 \\
\hline \multicolumn{4}{|l|}{ (2) Batting } \\
\hline \multicolumn{2}{|c|}{ Australia } & \multicolumn{2}{|c|}{ West Indies } \\
\hline Player & Performance Score & Player & Performance Score \\
\hline Slater & 60 & Lara & 90 \\
\hline Langer & 85 & Chanderpaul & 65 \\
\hline M. Waugh & 52 & Jacobs & 39 \\
\hline S. Waugh & 70 & Sarwan & 53 \\
\hline Ponting & 100 & Gayle & 57 \\
\hline Gilchrist & 76 & Hinds & 51 \\
\hline Martyn & 72 & Ganga & 38 \\
\hline Hayden & 89 & Hooper & 56 \\
\hline Katich & 56 & Campbell & 38 \\
\hline Clark & 58 & Adams & 27 \\
\hline Average & 71.9 & Average & 51.5 \\
\hline Index & 100 & Index & 72 \\
\hline Weighting & 1.0 & Weighting & 0.72 \\
\hline
\end{tabular}

Source: $\underline{\text { www.cricinfo.com }}$

The implication behind these weightings is that it is considerably easier to score runs and take wickets against the West Indies than it is against Australia: On a like for like basis, a run scored against the West Indian bowling attack is worth 0.82 runs scored against the Australian bowling attack and an Australian wicket is the equivalent of 0.72 West Indian wickets. Table F summarises the calculations made to assess the competitiveness of individual players for the same examples used in Table 7. 
Table 7: $\quad$ Competitiveness Measurement of 8 Batsmen and 8 Bowlers

\begin{tabular}{|c|c|c|c|c|c|c|c|c|}
\hline \multicolumn{9}{|l|}{ (1) Batting } \\
\hline & Ponting & Thorpe & Dravid & Horne & $\begin{array}{l}\text { Afrid } \\
\mathrm{i}\end{array}$ & Cullinan & Dilshan & Lara \\
\hline $\begin{array}{l}\text { Average runs per } \\
\text { innings scored } \\
\text { overseas }\end{array}$ & 87 & 84 & 100 & 38 & 58 & 99 & 48 & 75 \\
\hline $\begin{array}{l}\text { Weighted runs } \\
\text { scored }\end{array}$ & 93 & 38 & 100 & 18 & 21 & 33 & 19 & 98 \\
\hline $\begin{array}{l}\text { Average weighted } \\
\text { runs scored per } \\
\text { innings }\end{array}$ & 100 & 79 & 89 & 43 & 61 & 86 & 52 & 87 \\
\hline $\begin{array}{l}\text { Balls faced per } \\
\text { innings }\end{array}$ & 75 & 58 & 100 & 55 & 36 & 82 & 45 & 75 \\
\hline $\begin{array}{l}\text { Frequency of } \\
\text { weighted centuries } \\
\text { scored }\end{array}$ & 94 & 61 & 56 & 17 & 50 & 89 & 17 & 78 \\
\hline Total & 449 & 320 & 444 & 171 & 226 & 389 & 180 & 414 \\
\hline $\begin{array}{l}\text { Competitiveness } \\
\text { Index }\end{array}$ & 100 & 71 & 99 & 38 & 50 & 87 & 40 & 92 \\
\hline \multicolumn{9}{|l|}{ (2) Bowling } \\
\hline & Lee & Giles & Khan & Nash & Younis & $\mathrm{Nel}$ & Murali & Walsh \\
\hline $\begin{array}{l}\text { Weighted wickets } \\
\text { taken }\end{array}$ & 43 & 29 & 22 & 17 & 26 & 19 & 100 & 38 \\
\hline $\begin{array}{l}\text { Weighted wickets } \\
\text { taken per innings }\end{array}$ & 53 & 47 & 43 & 50 & 47 & 53 & 100 & 70 \\
\hline $\begin{array}{l}\text { Runs conceded per } \\
\text { weighted wicket } \\
\text { taken }\end{array}$ & 56 & 48 & 50 & 68 & 57 & 63 & 86 & 91 \\
\hline $\begin{array}{l}\text { Overs bowled per } \\
\text { weighted wicket } \\
\text { taken }\end{array}$ & 81 & 53 & 62 & 68 & 75 & 74 & 80 & 81 \\
\hline $\begin{array}{l}\text { Top } 6 \text { opposition } \\
\text { wickets taken }\end{array}$ & 80 & 79 & 94 & 87 & 83 & 67 & 71 & 78 \\
\hline $\begin{array}{l}\text { Average wickets per } \\
\text { innings taken } \\
\text { overseas }\end{array}$ & 56 & 48 & 55 & 60 & 50 & 59 & 100 & 74 \\
\hline $\begin{array}{l}\text { Degree of internal } \\
\text { competition for } \\
\text { wickets }\end{array}$ & 85 & 89 & 90 & 87 & 88 & 86 & 68 & 80 \\
\hline Total & 453 & 394 & 416 & 438 & 426 & 421 & 604 & 511 \\
\hline $\begin{array}{l}\text { Competitiveness } \\
\text { Index }\end{array}$ & 75 & 65 & 69 & 72 & 71 & 70 & 100 & 85 \\
\hline
\end{tabular}

Source: www.cricinfo.com

The final issue for this section of the paper is to explain how the results of the analysis will be presented. The first step in this process will be to plot the performance and competitiveness scores on the chart in Figure 1. In plotting batsmen and bowlers on this chart, each player will occupy one of four general positions which are represented stylistically in Figure 1. 
Figure 1: $\quad$ Performance-Competitiveness Matrix

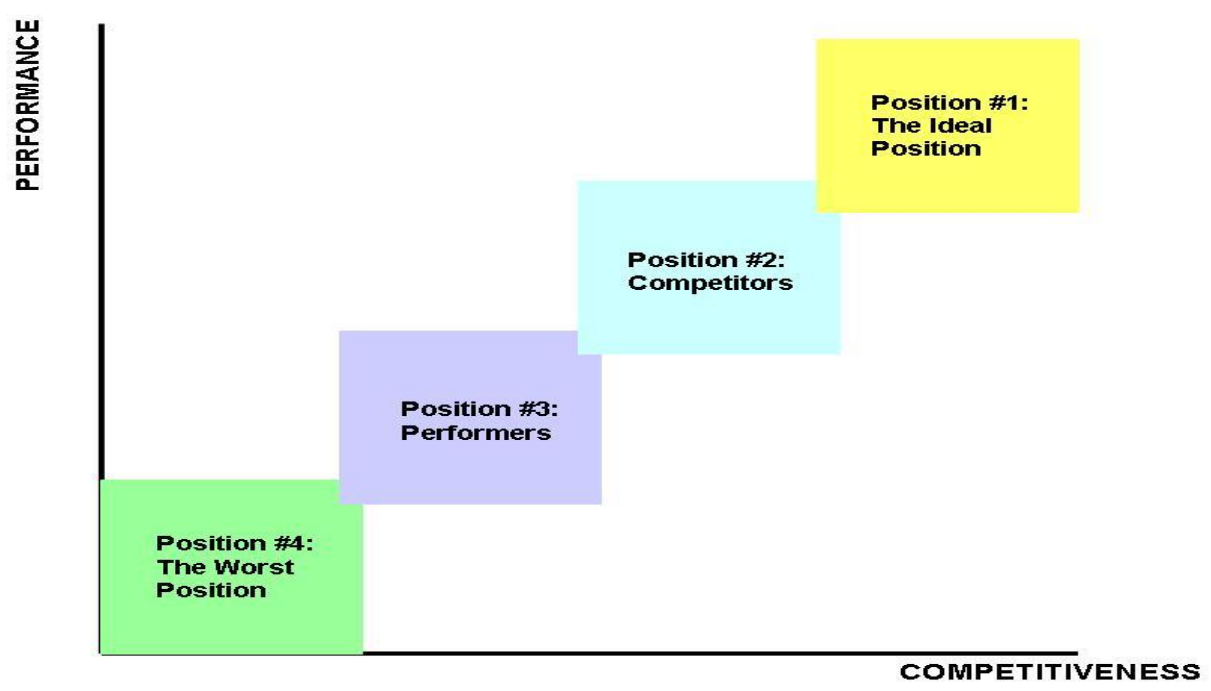

The first position, the ideal position, will be occupied by those players with both high performance and competitiveness scores. These will be those players whose runs scoring or wicket taking is consistently high regardless of who the opposition is or where the match is played. The second position, competitors, will be occupied by players whose prime contribution to the team will be through their competitiveness; these are batsmen who will, for example, perform best against the best opposition or bowlers who may focus their wicket taking on top 6 batsmen. The third position, performers, will be occupied by players who will tend to contribute most to the team when competitive pressure is lowest. These may be batsmen or bowlers whose best performances are in matches played at home or against relatively weak opposition. The final position, the worst position, is for those players who contribute the least in term of both performance and competitiveness. For example, these players may be all rounders who offer just average performance with both bat and ball.

\section{Findings}

As one of the aims of this paper is to consider the relationship between a specific form of team diversity and the outcomes enjoyed by teams in test match cricket, we begin this section with a discussion of outcomes. Table 8 summarises the results of the 100 matches played by each team in our sample and identifies a number of key issues for the analysis which follows. Two teams stand out clearly from the sample. First, Australia stand out as having significantly better results than everyone else: Over the period, they have won over a third more matches than their nearest rivals and have lost just half the number of matches of their nearest rivals. Second, the West Indies stand out as being significantly worse that all the other teams in the sample having won less than one in five matches played and lost almost two-thirds. 
Table 8: $\quad$ Matches won, lost and drawn by each team in the sample

\begin{tabular}{|l|c|c|c|}
\hline & Matches Won & Matches Lost & Matches Drawn \\
\hline Australia & 69 & 15 & 16 \\
\hline South Africa & 43 & 30 & 27 \\
\hline England & 38 & 36 & 26 \\
\hline Pakistan & 36 & 37 & 27 \\
\hline India & 27 & 33 & 40 \\
\hline Sri Lanka & 26 & 42 & 32 \\
\hline New Zealand & 22 & 43 & 35 \\
\hline West Indies & 16 & 58 & 26 \\
\hline
\end{tabular}

Source: $\underline{w w w . c r i c i n f o . c o m}$

The remaining six teams can be broadly aligned into two groups. The first group (South Africa, England and Pakistan) can be grouped together as they have a very similar level of wins, losses and draws and, for the same reason, India, Sri Lanka and New Zealand can also be grouped together. From this we would identify two questions which will frame the presentation of the results and analysis of the performance-competitiveness orientation composition of each team. The first, and most obvious question, is why are Australia so good and the West Indies so bad? The second question focuses on the two groups of remaining teams and concerns the extent to which there may be similarities (or differences) in composition which could help explain the similarities in results achieved.

Before addressing these two specific questions, we first discuss the issue of temporal diversity and Table 9 offers data on the number of players used in the 100 matches played by each team and the average number of appearances made by each player. This suggests a possible relationship between team outcome and the longevity of team membership. For example, the best team, Australia, has used the fewest players in the sample and has the most experienced players in the sample. On the other hand, the West Indies (along with Pakistan and New Zealand) have used the most players and have picked teams with the least experienced members. The literature on team diversity (see, for example, Katzenbach, McGrath and Bettenhausen) would suggest that these characteristics would bring benefits to Australia in terms of experience, stability and the development of efficient team processes but it remains unclear as to what is the cause and what is the effect in the relationship between team longevity and results; Have Australia been the most successful because they have had the most experienced and stable team or is that success the precondition on which stability is built?

Table 9: $\quad$ Number of players and average appearance per player

\begin{tabular}{|l|c|c|c|c|c|c|c|c|}
\hline & Australia & England & India & $\begin{array}{c}\text { New } \\
\text { Zealand }\end{array}$ & Pakistan & $\begin{array}{c}\text { South } \\
\text { Africa }\end{array}$ & Sri Lanka & $\begin{array}{c}\text { West } \\
\text { Indies }\end{array}$ \\
\hline $\begin{array}{l}\text { Number of } \\
\text { players } \\
\text { used }\end{array}$ & 40 & 68 & 67 & 71 & 72 & 51 & 60 & 70 \\
\hline $\begin{array}{l}\text { Average } \\
\text { appearances } \\
\text { per player }\end{array}$ & 22.7 & 16.7 & 17.4 & 16.7 & 16.3 & 22.2 & 19.4 & 16.2 \\
\hline
\end{tabular}

Source: $\underline{w w w . c r i c i n f o . c o m}$

We now turn to discuss the performance and competitive orientation composition of the different teams and begin with a consideration of the best and worst teams in the sample. Figure 2 presents the composition diagrammatically for the batsmen in each team's sample. The most obvious difference between these two teams is that Australia's batsmen tend to be located towards the top of the spectrum and, with a couple of exceptions, the West Indies batsmen are located towards the bottom; $60 \%$ of Australia's batsmen occupy the Ideal 
Position or Competitor boxes compared to the $80 \%$ of West Indies batsmen who occupy the Worst Position and Performer boxes. This suggests that there are two distinct types of diversity present in the two teams. The Australian diversity clusters around high levels of competitiveness whereas the West Indian diversity tends to cluster around low levels of competitiveness.

Figure 2: $\quad$ Australia and West Indies performance and competitive orientation: Batting

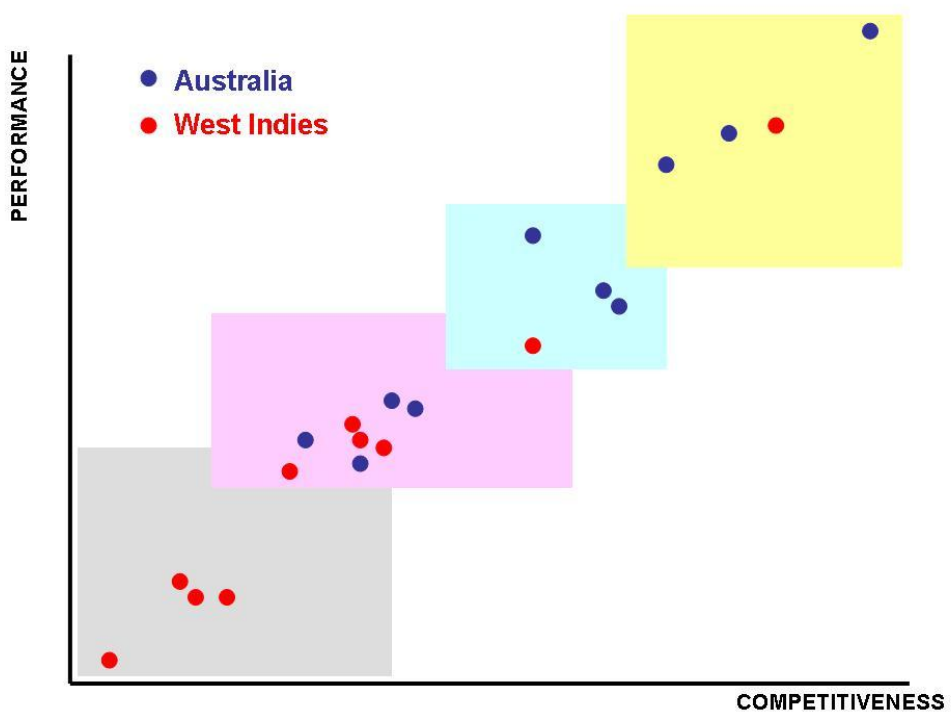

Source: www.cricinfo.com

The composition of the bowling dimension of each team, as shown in Figure 3, has a similar pattern; over the course of the 100 games under consideration, Australia have two of their six bowlers occupying the Ideal Position box compared to the West Indies who have three out of seven bowlers occupying the Worst Position box. The obvious point to make from this evidence about batting and bowling is that the main advantage Australia draw from this team composition is the combination of players who can make a contribution to team outcomes across the whole of a test match and under a variety of conditions. For example, the evidence suggests that the Australian team has the performance characteristics which can put them in a position where winning a match is a real possibility and also the competitive characteristics which allow them to drive home that advantage. The West Indies, on the other hand, do not have the performance characteristics to put themselves into positions where winning test matches is possible on a consistent basis and, even when they do, they lack of the necessary competitive dimension to their team dynamics which would allow them to take advantage. 
Figure 3: $\quad$ Australia and West Indies performance and competitive orientation: Bowling

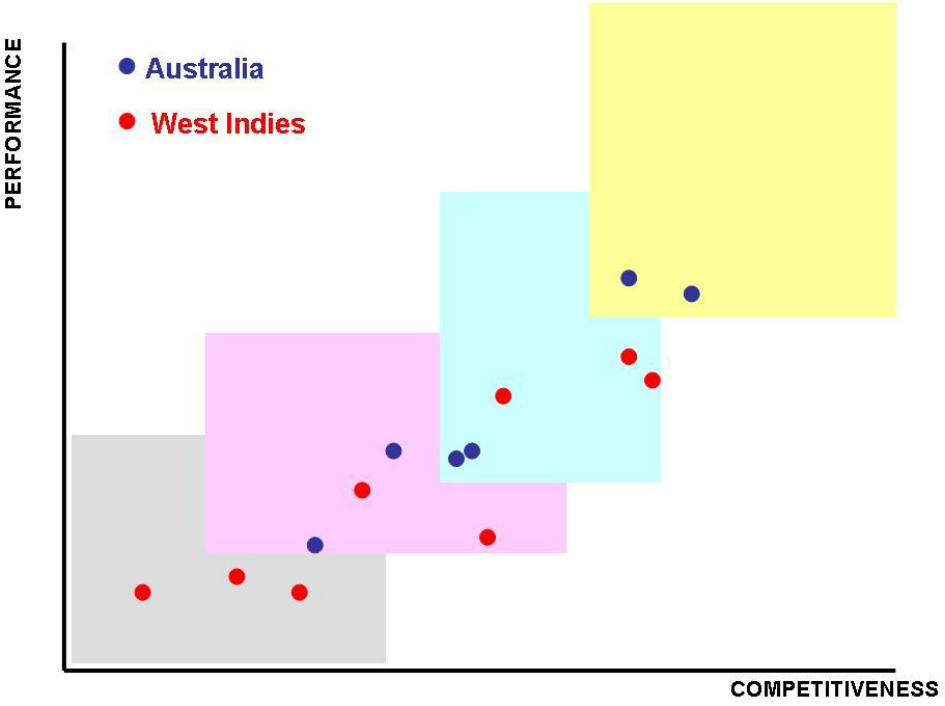

Source: $\underline{w w w . c r i c i n f o . c o m}$

The most striking difference between the two outstanding teams and the first group of teams (South Africa, England and Pakistan) is that the group of teams have many more players located in the centre of the performance-competitiveness matrix. Figure 4 shows this point in terms of batting where the overriding difference between these teams and Australia is that South Africa, England and Pakistan have many players who can offer either performance or competitiveness whereas Australia have a significant number of batsmen and bowlers who can offer both. In batting terms this issue is further compounded by all three teams having a significant number of players at the bottom of the performance-competitiveness matrix who make a limited contribution in both areas. In the cases of South Africa and Pakistan, any strength of the team at the top end of the matrix would seem to be, at best, negated by even more significant weaknesses at the bottom.

Figure 4: $\quad$ South Africa, England and Pakistan performance and competitive orientation: Batting

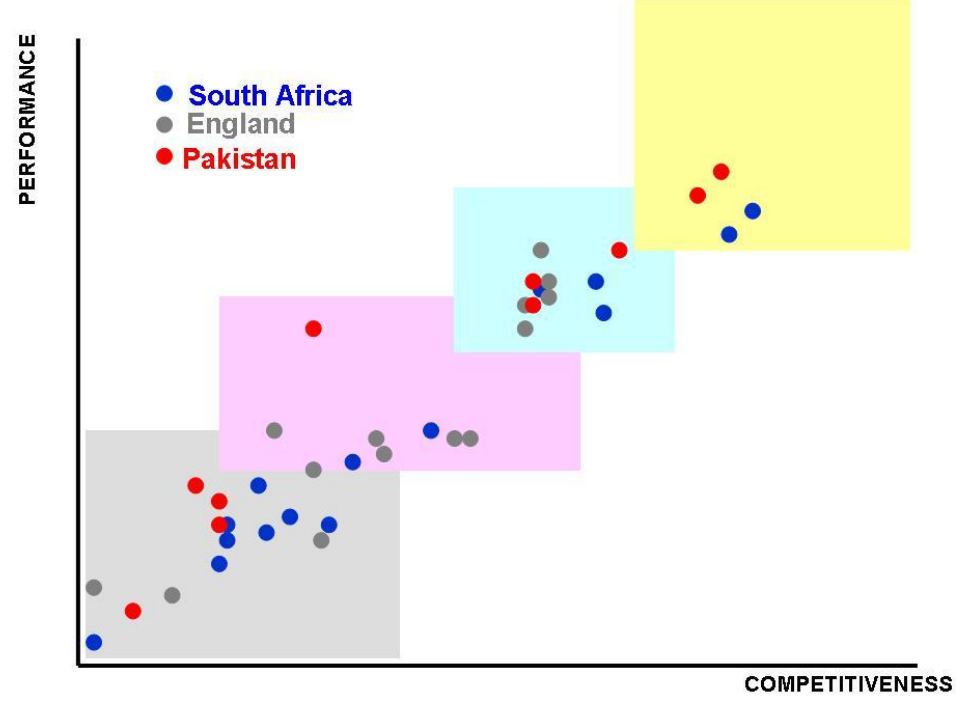

Source: $\underline{w w w . c r i c i n f o . c o m}$ 
With one exception, as Figure 5 shows, none of these three grouped teams have any bowlers who can offer both high levels of performance and high levels of competitiveness. Given the limited bowling resources available to all teams in test match cricket, the outcome of this composition is that these teams will be made up of bowlers who are likely to, for example, take wickets in either a less pressurised first innings before the result of the match is decided or competitive bowlers who can take wickets in a second innings under more pressure but, frequently, after a match's outcome is pretty much decided. The combination of scarce resources and a limited set of KSAs within those resources is a reasonably convincing explanation as to why these teams have been unable to move up a level and secure the results enjoyed by Australia.

Figure 5: $\quad$ South Africa, England and Pakistan performance and competitive orientation: Bowling

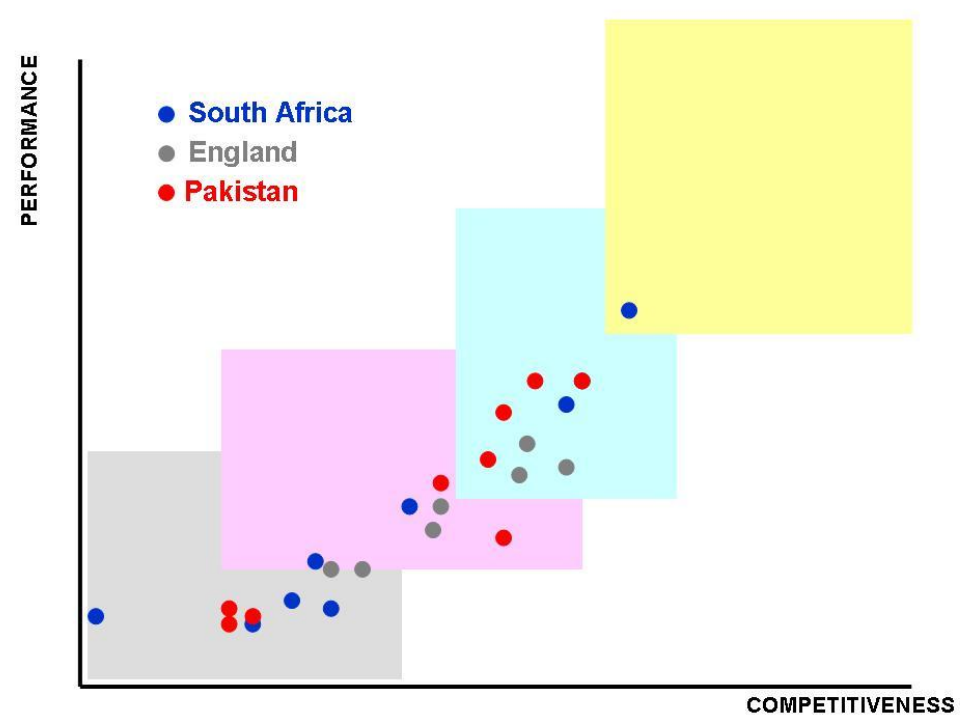

Source: $\underline{w w w . c r i c i n f o . c o m}$

The analysis and conclusions from the data become much less clear, however, when we consider the final three teams in the second grouping from the sample. For example, if we consider batting (see Figure 6) we see that whilst there is a large degree of similarity in results between these teams there is less similarity in terms of composition. Whilst New Zealand and Sri Lanka share very similar composition characteristics with players located towards the bottom end of the matrix, the case of India is in marked contrast with a batting composition that more resembles that of Australia than it does that of the West Indies: The composition of the Indian team has three players occupying the Ideal Position box and just one player in the Worst Position box. 
Figure 6: $\quad$ India, New Zealand and Sri Lanka performance and competitive orientation: Batting

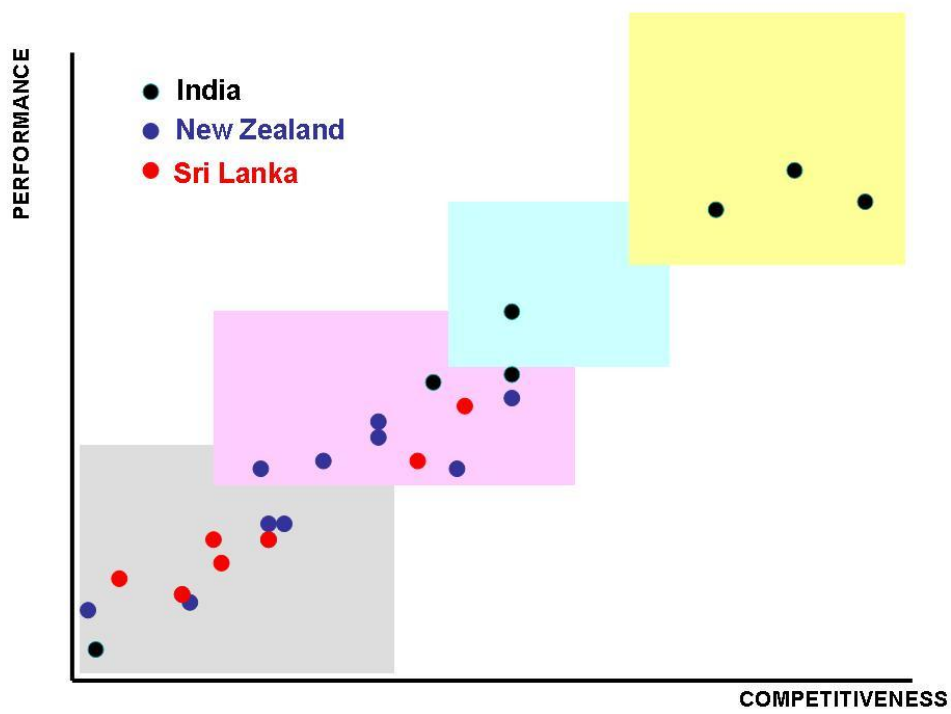

Source: www.cricinfo.com

The bowling characteristics of these teams does, though, suggest a possible explanation for their overall poor results. In all three cases, there is a clear tendency for bowlers to be located towards the bottom of the performance-competitiveness matrix and this is most striking in the case of New Zealand who have no bowlers who even come close to occupying the Ideal Position box. On the other hand, both India and Sri Lanka have one bowler in this position but, as we have seen before, strength at the top cannot always overcome significant weaknesses elsewhere. This evidence may also suggest that it is strength in bowling, rather than batting, which is more important in determining the outcome of test matches; the real and overwhelming advantage enjoyed by Australia is the blend of performance and competitiveness which gives them strengths in both areas.

Figure 7: $\quad$ India, New Zealand and Sri Lanka performance and competitive orientation: Bowling

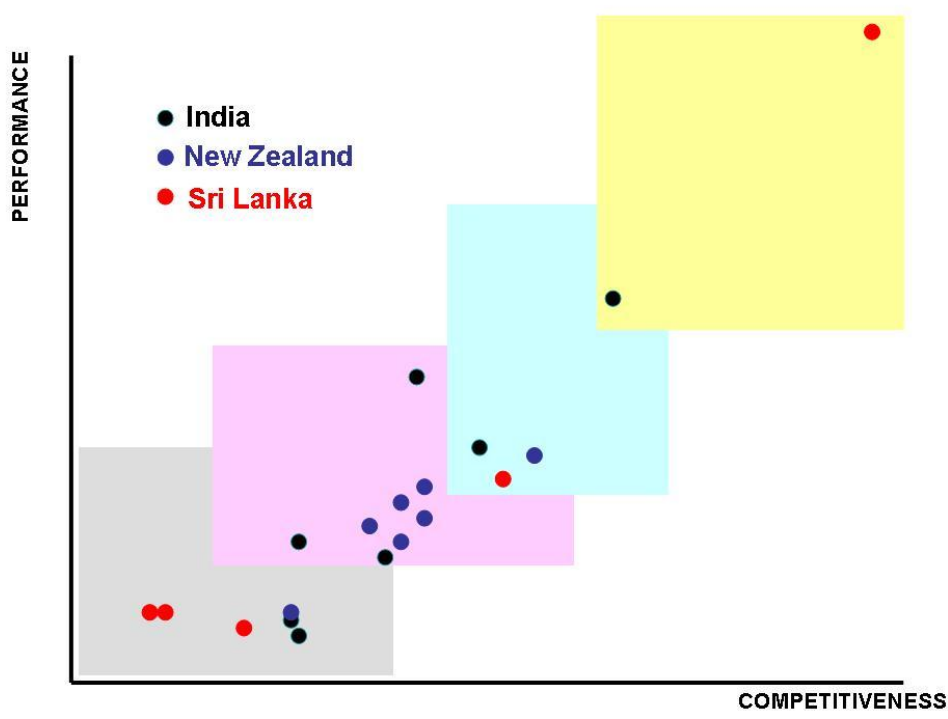

Source: $\underline{w w w . c r i c i n f o . c o m}$ 
We now turn to conclude the paper by reflecting on these findings in relation to the literature review with which the paper commenced.

\section{$\underline{\text { Discussion and Conclusions }}$}

The most obvious conclusion to draw from the theory and evidence presented in this paper is that, whilst measuring the outcomes of a team activity is simple and straightforward, especially in a sporting context, identifying and measuring the causes of those outcomes is much more complex and difficult. This can hardly be a surprising conclusion as it fits in neatly with Barrick et al's point about the general uncertainty in the literature about this relationship. What the evidence in this paper does suggest, however, is that perhaps the relationship between outcomes and processes if not so much a linear relationship, as implied by the IPO model, but rather a circular one where, over time, a run of results will inevitably have an impact on inputs and processes. Where results go badly, teams will be more likely to make changes to their composition and how that composition is managed and organised. Even with a sample of matches as large as ours, all we are able to offer is an (extended) snapshot of one period in a much longer cycle which may be a weakness others would like to remedy.

If the evidence is unclear about the causal relationship between composition and outcome, it is still possible to draw some clear conclusions about diversity in teams, albeit conclusions which are probably specific to this particular context. In terms of temporal diversity, the best team has the most experienced players and is the most stable compared to the worst team which is amongst the least stable and has the least experienced players. Similarly, the best team has the best players and the worst team has the worst players. Finally, teams grouped around the middle in terms of outcomes and results have a collection of players who cluster around the average. Again, there is little controversy between these conclusions and the established theory on the issues although they do raise some interesting questions about the dynamism of sporting contests. Over the long term, in our case 100 matches spread over nearly thirteen years, the best team will always come out on top but, in the shorter term, that is not always the case. In 2005, for example, England were able to beat Australia despite having poorer playing resources available. This could be explained by Woodman et al's point that team characteristics are a "function" of individual characteristics rather than an aggregate and it raises important issues about why such outcomes are not always sustainable.

If conclusions about composition are difficult to sustain, conclusions about activities in a team context maybe easier to draw. In the game of cricket, some activities are more important than others in determining outcomes. For example, bowling may be more important than batting for the simple reason that you may only need to bat once to win a test match but you always have to bowl twice. Focusing resources on the most important activities is a key less on from this although both the theory and practice show the limits of what is possible. Test match teams, like most organisations, operate from the basis of limited available resources. Reagans et al's argument about a finite poor of available KSAs offers an accurate reflection of this problem in cricket and raises the issue of compromise; international teams will never be able to muster players who all have high levels of performance and competitive orientation and must make the best of what they have available. On the input side, this raises key questions about where those resources come from and how they can be generated.

In a paper of this scope and this length, it is inevitable that it will offer more by way of illustrating controversies and debates than it will in terms of settling controversies and debates. Whilst we are reasonably clear and certain about what our analysis means in the specific context of test match cricket, we are much more equivocal about what all this means in the wider discussion of team dynamics, team composition and their relationship with team outcomes. Our main conclusion will always be that there is still much more work to be done before these issues are settled once and for all. 
$\underline{\text { References }}$

Adcroft, A. and Teckman, J. (2008) Theories, concepts and the Rugby World Cup: Using management to understand sport in Management Decision, volume 46, number 4. pp 600-625

Barrick, M. R., Stewart, G. L., Neubert, M. J. and Mount, M. K. (1998) Relating member ability and personality to work team processes and team effectiveness in Journal of Applied Psychology, volume 83, number 3. pp 377-391

Barry, B. and Stewart, G. L. (1997) Composition, process and performance in selfmanaged groups: The role of personality in Journal of Applied Psychology, volume 82, number 1. pp 62-78

Bettenhausen, K. (1991) Five years of group research: What we have learnt and what needs to be addressed in Journal of Management, volume 17, number 2. pp 345-381

Cohen, S. G. and Bailey, D. E. (1997) What makes teams work: Group effectiveness research from the shop floor to the executive suite in Journal of Management, volume 23, number 3. pp 239-290

Gatignon, H. and Xuereb, J-M. (February 1997) Strategic Orientation of the Firm and New Product Performance in Journal of Marketing Research, volume 34. pp 77-90

Guzzo, R. A. and Dickson, M. W. (1996) Teams in organisations: Recent research on performance and effectiveness in Annual Review of Psychology, volume 47. pp 307-338

Hambrick, D. C., Cho, T. S. and Chen, M-J (1996) The influence of top management teams heterogeneity on firms' competitive moves in Administrative Science Quarterly, volume 41. pp 659-684

Harrison, D. A., Price, K. H., Gavin, J. H. and Florey, A. T. (2002) Time, teams and task performance: Changing effects of surface and deep level diversity on group functioning in Academy of Management Journal, volume 45, number 5. pp 1029-1045

Huddleston, S. and Garvin, G. W. (September 1995) Self-evaluation compared to coaches evaluation of athletes competitive orientation in Journal of Sports Behaviour, volume 18, issue 3. pp 209-215

Jackson, S. E. (1992) Consequences of group composition for the interpersonal dynamics of strategic issue processing in Advances in Strategic Management, volume 8. pp 345-382

Katzenbach, J. R. (1997) The myth of the top management team in Harvard Business Review, November-December. pp 1883-1891

Le Pine, J. A., Hollenbeck, S. R., Ilgen, D. R. and Hedlund, J. (1997) Effects of individual differences on the performance of hierarchical decision-making teams: more than just $g$ in Journal of Applied Psychology, volume 82, number 5. pp 803-811

Matthieu, J. E., Heffner, T. S. and Goodwin, G. F., Eduardo, S. A. and ChannonBowers, J. A. (2000) The influence of shared mental models on team process and performance in Journal of Applied Psychology, volume 85, number 2. pp 273-283

McGrath, J. E., Arrow, H. and Berdahl, J. L. (2000) The study of groups: past, presence and future in Personality and Social Psychology Review, volume 4, number 1.pp 95-105

Perretti, F. and Negro, G. (2007) Mixing genres and matching people: a study of innovation and team composition in Hollywood in Journal of Organisational Behaviour, volume 28. pp 563-586

Reagans, R., Zuckerman, E. and McEvily, B. (2004) How to make the team: Social networks vs democracy as criteria for designing effective teams in Administrative Science Quarterly, volume 49. pp 101-133

Ryckman, R. M., Libby, C. R., van den Borne, B., Gold, J. A. and Linder, M. A. (1997) Values of hypercompetitive and personal development competitive individuals in Journal of Personality Assessment, volume 69, number 2. pp 271-283

Salas, E., Shawn Burke, C. and Cannon-Bowers, J. A. (2000) Teamwork: Emerging principles in International Journal of Management Reviews, volume 2, issue 4. pp 339-356 
Simons, J., Dewitte, S. and Lens, W. (2000) Wanting to have vs. wanting to be: The effect of perceived instrumentality on goal orientation in British Journal of Psychology, volume 91. pp 335-351

Stahl, G. K., Maznevski, M., Voight, A. and Jonsen, K. (2007) Unravelling the diversity-performance link in multi-cultural teams: Meta-analysis of studies on the impact of cultural diversity in teams in Insead Faculty Research Working Paper, 2007/36/OB

Stevens, M. J. and Campion, M. A. (1994) The knowledge, skill and ability requirements for teamwork: Implications for human resource management in Journal of Management, volume 20, number 2. pp 503-530

Stiles, P., Gratton, L., Truss, C., Hope-Hailey, V. and McGovern, P. (1997) Performance management and the psychological contract in Human Resource Management Journal, volume 7, number 1. pp 57-66

Wiersama, M. F. and Bantel, K. A. (1992) Top management team demography and corporate strategic change in Academy of Management Journal, volume 35, number 1. pp 91-121

Woodman, R. W., Sawyer, J. E. and Griffin, R. W. (1993) Towards a theory of organisational creativity in Academy of Management Review, volume 18, number 2. pp 295321

$\underline{\text { www.cricinfo.com }}$ 